\title{
Luís da Câmara Cascudo e Mário de Andrade, uma amizade epistolar
}

\author{
Luís da Câmara Cascudo and Mário de Andrade, an epistolary friendship
}

\section{Raquel Silva Maciel}

Doutoranda em História no Programa de Pós-graduação em História da UFC quequelpb@hotmail.com

\begin{abstract}
Resumo: A epistolografia caracteriza-se como uma forma essencialmente dialogada que expõe dados biográficos, literários e históricos e possibilita instituir uma proximidade a partir da continuidade da correspondência ou da tentativa de estabelecêla. Tudo que pode ser dito e/ou escrito é capaz de ser objeto da carta. Essas se expressam não só pelas palavras que contém, mas por elementos como os silêncios. Portanto, são significativas para a compreensão das sociabilidades instituídas entre um conjunto de pessoas, que são ligados por interesses comuns, como os intelectuais. Nessa perspectiva, apresentamos considerações acerca da escrita epistolar, a partir da prática desenvolvida entre Luís da Câmara Cascudo e Mário de Andrade, atentando para o uso da epistolografia como espaço propício para o processo de criação intelectual e para o florescimento de relações afetivas fortes e duradouras.
\end{abstract}

Palavras-chave: Correspondências; Luís da Câmara Cascudo; Mário de Andrade.
Abstract: Epistolography is characterized as an essentially dialogued form that exposes biographical, literary and historical data and makes it possible to establish a proximity based on the continuity of correspondence or the attempt to establish it. Everything that can be said and/or written is capable of being the subject of the letter. These are expressed not only by the words they contain, but by elements such as silences. Therefore, they are significant for understanding the sociabilities established between a group of people, who are linked by common interests, such as intellectuals. From this perspective, we present considerations about epistolary writing, based on the practice developed between Luís da Câmara Cascudo and Mário de Andrade, paying attention to the use of epistolography as a favorable space for the process of intellectual creation and for the flourishing of strong and lasting affective relationships.

Keywords: Letters; Luís da Câmara Cascudo; Mário de Andrade.

\footnotetext{
* O artigo apresenta resultados parciais de uma pesquisa de doutoramento desenvolvida na Universidade Federal do Ceará junto ao Programa de Pós-graduação em História e financiada pela Coordenação de Aperfeiçoamento de Pessoal de Nível Superior.
} 


\section{A sociabilidade entre intelectuais}

A sociabilidade pode ser interpretada enquanto mobilizada por necessidades singulares em espaços nos quais os sujeitos se agrupam em torno de interesses comuns, adotando, por meio do convívio, formas de cooperação e de colaboração. Tais características

fazem com que os homens se unam em associações econômicas, em irmandades de sangue, em sociedades religiosas, em quadrilhas de bandidos. Além de seus conteúdos específicos, todas estas sociações também se caracterizam, precisamente, por um sentimento, entre membros, de estarem sociados, e pela satisfação derivada disso (grifo nosso) (SIMMEL, 1983: 168).

Considerando que, a sociedade pode ser entendida enquanto um "estar com um outro, para um outro, contra um outro" (SIMMEL, 1983: 168), as sociabilidades podem ser compreendidas como derivadas das experiências, opiniões e relações sociais vividas por sujeitos em locais específicos através do tempo. No campo intelectual, a sociabilidade permite compreender as interações do sujeito com os seus pares, afastando-se da análise do intelectual de forma isolada, oportunizando identificar as influências mútuas que exercem nos círculos intelectuais que compõem. Interpretandoas como mecanismo para compreensão da organização e dinâmica do campo intelectual e, consequentemente, revelando amizades e inimizades, vínculos e cisões.

Considerando isso, a formação de redes de sociabilidade pode ser interpretada enquanto uma busca por legitimação por meio da inserção do sujeito em diferentes grupos. Possibilitando o desenvolvimento e compartilhamento de sensibilidades e projetos, além de oportunizar que os pertencentes a tal coletividade revelem seus posicionamentos intelectuais, políticos e sociais. Nessa perspectiva,

o intelectual precisa estar envolvido em um circuito de sociabilidade que, ao mesmo tempo, o situe no mundo cultural e lhe permita interpretar o mundo político e social de seu tempo. Por isso, afirma-se que não é tanto a condição de intelectual que desencadeia uma estratégia de sociabilidade e sim, ao contrário, a participação numa rede de contatos é que demarca a específica inserção do intelectual num mundo cultural. Intelectuais são, portanto, homens cuja produção é sempre influenciada pela participação em associações, mais ou menos formais, e em uma série de outros grupos, que se salientam por práticas culturais de oralidade e/ou escrita (grifo nosso) (GOMES, 2004: 51).

Prática habitual no campo intelectual, as correspondências são documentos produzidos, frequentemente, no domínio privado, que indicam traços das redes de 
sociabilidade política e intelectual de sujeitos anônimos ou célebres. Constituindo, em determinado momento, círculos nos quais os correspondentes se comunicavam e debatiam ideias por meio da troca de missivas, coletividade denominada de geração do recado $(\mathrm{GICO}, \mathrm{S} / \mathrm{D})$.

A epistolografia, ao ser interpretada como espaço para o fomento da rede de sociabilidade, oportuniza a identificação das correspondências como um arquivo de criação o que, por sua vez, permite compreender a prática missivista desenvolvida por intelectuais como Luís da Câmara Cascudo. O folclorista, a quem é atribuído o posto de um dos maiores epistológrafos do Brasil, manifesta, na escrita epistolar, o percurso explorado para a construção de pesquisas, apontando, entre outras questões, os estágios de produção, as dificuldades e dúvidas na criação intelectual, os comentários sobre a produção literária e artística contemporânea, as divergências entre grupos, os mecanismos utilizados para a circulação e divulgação de um projeto estético, assim como a recepção dos escritos produzidos por ele.

Com a prática epistolar desenvolvida por Luís da Câmara Cascudo, a própria rede de sociabilidade pôde ser favorecida, visto que as cartas perguntadeiras ${ }^{1}$, a título de exemplo, possibilitavam a obtenção de endereços de outros sujeitos com os quais desejava se comunicar. Além de oportunizar a inserção de intelectuais, indiretamente, nos círculos de amizade, por meio, por exemplo, da menção a um nome já conhecido por alguma das partes, assim, a rede construída ampliava-se.

A escrita epistolográfica põe em evidência um jogo interno de omissões, consentimentos e exaltações entre as sociabilidades construídas por intelectuais. Considerando isso, pode ser interpretada como espaço de experiências e de partilhas possibilitando, por meio da identificação dos sujeitos denominados por Luís da Câmara Cascudo de "vítimas indefesas", compreender de que forma essas correspondências são permeadas pelo discurso do outro e de que maneira aqueles que se comunicam se colocam no texto. Nessa perspectiva, "o epistológrafo é, portanto, em todos os planos íntimo, literário, cultural - um transmissor" (DIAZ, 2016: 109), além de produtor de uma espécie de "retrato do autor" que reafirma, confronta ou contesta a imagem dele, já que se trata de uma identidade variável de acordo com os correspondentes. Assim,

\footnotetext{
1 As colaborações intelectuais desenvolveram-se a partir de movimentos diversos. Porém, eram intermediadas pelo que o folclorista denominava de "cartas perguntadeiras", isto é, correspondências direcionadas às instituições, amigos e/ou pesquisadores que apresentavam pedidos como o envio de livros, contatos, documentos, fotografias, trabalhos e outros elementos que possibilitaram, em diversos momentos, que Luís da Câmara Cascudo percorresse o Brasil em busca dos elementos folclóricos sem deslocar-se do seu gabinete.
} 
mesmo que a carta seja enviada para vários sujeitos, ela sempre passará por modificações e são elas que refletem o "novo" eu, o que possibilita compreender que a carta não se encontra ancorada em uma noção de identidade fixa, mas sim mutável.

A conversação estabelecida com tais sujeitos reflete a construção de relacionamentos, a influência na formação discursiva do folclorista - exemplificado a partir da similaridade que possui, com alguns desses intelectuais, no tocante a interpretação do elemento folclórico - e o seu direcionamento para tomar o folclore enquanto objeto de pesquisa, nessa perspectiva, a prática epistolográfica que desenvolve com Mário de Andrade é elucidativa.

\section{Quer acamaradar-se? A emergência de um aparceiramento intelectual}

Correspondendo-se com inúmeros destinatários a partir da abordagem de uma diversidade de assuntos e projetos estéticos, Mário de Andrade é detentor do arquivo de correspondências, considerado, por pesquisadores, como o mais expressivo do século XX. Entre as características que compõe a escrita epistolar do poeta está a de aconselhamento do ingresso no mundo das letras a partir do desenvolvimento da prática missivista, caracterizando o seu produtor como um dos primeiros escritores brasileiros a pensar certa especificidade para o gênero epistolar. $\mathrm{O}$ ato de corresponder-se com intelectuais situados tanto no Brasil quanto no exterior era, em certa medida, motivado pelo desejo de trocar informações, realizar reflexões e debater questões.

Mário de Andrade, referenciado por Luís da Câmara Cascudo no Dicionário do Folclore Brasileiro como um "grande estudioso do folclore, observador etnográfico insuperável" (CASCUDO, 1954: 173) e como aquele que "sua presença nos estudos do folclore brasileiro é diária e sensível" (CASCUDO, 1954: 173) ocupa posição de destaque na rede de sociabilidade que Luís da Câmara Cascudo construiu, foi por meio da troca de correspondências que a amizade entre eles despertou e se efetivou.

A emergência da troca de correspondências entre eles ocorre a partir da resposta que Mário de Andrade enviou para Luís da Câmara Cascudo, em 14 de agosto de 1924, agradecendo a redação do artigo intitulado O Sr. Mário de Andrade, publicado no periódico A Imprensa daquele ano. Além disso, menciona que já conhecia Luís da Câmara Cascudo por meio de uma pesquisa, acerca das temáticas sertanejas, publicada na Revista do Brasil pelo escritor norte-rio-grandense, classificando o estilo cascudiano 
como aquele que provoca o entretenimento por caracterizar-se como "vivaz, serelepe" (MA, 14-VIII-1924, apud, CASCUDO, 2010: 33). Por fim, sugere que sempre terá interesse nos trabalhos do folclorista e incita-o a mandá-los. Com isso, indica o desejo de continuidade na troca de cartas, que é intensificado ao afirmar que não esquecerá mais dele, sendo grato por saber da sua existência, da existência de mais uma inteligência.

Onze dias após o envio da correspondência assinada por Mário de Andrade, em 25 de agosto de 1924, Luís da Câmara Cascudo responde afirmando que ao manifestar a vontade de conhecê-lo acabou por assanhar uma caixa de maribondo, por isso, junto com a carta envia dois livros de sua autoria - apresentando $\mathrm{Joio}^{2}$ como o que tem realizado de melhor (CC, 25-VIII-1924, apud, CASCUDO, 2010). Intitula-se como um dos admiradores de Mário de Andrade e consequentemente, curioso em saber o que pensa sobre as obras que encaminhou. Ao pedir que o escritor paulista mande uma fotografia de si acaba por sugerir o desejo de não só manter correspondência, mas de enxergar aquele com quem se comunica. Por fim, ao incentivar que repasse algo de sua autoria para que possa publicar em uma revista da região nos sugestiona que a conversação estabelecida entre eles caminha para o despertar de uma parceria intelectual, evidenciando que as cartas com Mário de Andrade são regidas, principalmente, pelas expectativas em relação ao trabalho.

Só na correspondência de 26 de setembro de 1924 há uma resposta para Luís da Câmara Cascudo, quando o poeta menciona ter lido todo o material enviado pelo folclorista e que a partir disso realizou algumas críticas aos livros, declarando tratar-se de uma opinião particular³ ${ }^{3}$ Avalia as produções afirmando que, por vezes, Luís da Câmara Cascudo utiliza imagens eruditas que em nada servem, induzindo que as comparações devem ser feitas com coisas que ele "vê, toca, não com o que leu nos livros" (MA, 26-IX-1924, apud, CASCUDO, 2010: 39), apesar disso, o potiguar continuou utilizando tal prática na redação dos seus escritos.

O relacionamento entre ambos é pormenorizado na missiva, de 26 de novembro de 1925, enviada pelo paulista, na qual declara que o convívio estabelecido entre eles não cedeu espaço para tratamentos formais, sugerindo que a proximidade na relação

\footnotetext{
${ }^{2}$ Publicada no ano em que inicia a conversação com Mário de Andrade, a obra apresenta ensaios críticos produzidos por Luís da Câmara Cascudo sobre a produção literária daquele período.

${ }^{3} \mathrm{O}$ compartilhamento de rascunhos, trechos e até obras completas oportuniza que o remetente tenha no destinatário a possibilidade de fazer-se lido e antecipar possíveis críticas. Trata-se de convidar o correspondente para participar do processo de criação literária e com isso garantir que estará protegido à sombra do correspondente (HAROCHE-BOUZINAC, 2016).
} 
oportunizou que o silêncio fosse algo confortável e que as semelhanças se acentuassem ao ponto de torná-los um só, partilhando a existência de si, assim, afirma

na nossa amizade, Luís, me parece que já passamos o tempo do aperto de mão e do "você" apenas... Já estamos no período mais amigo em que a gente pode passar dez minutos um ao lado do outro, sem falar, sem procurar assunto, vivendo apenas a vida uma só de dois iguais e bem se conhecendo. É doce viver a existência do amigo... Às vezes me ponho matutando no que você estará fazendo, de certo acendeu o cigarro, não, está bebendo refresco de abacaxi debaixo das árvores (grifo nosso) (MA, 26-XI-1925, apud, CASCUDO, 2010: 76-77).

Partiu do escritor paulista, a sugestão para que o pesquisador potiguar priorizasse em seus estudos a análise do elemento folclórico. Assim, em carta datada de 09 de junho de 1937, afirma "você tem a riqueza folclorista passando aí na rua a qualquer hora. Você tem todos os seus conhecidos e amigos do seu Estado e Nordeste para pedir informações" (grifo nosso) (MA, 09-VI-1937, apud, CASCUDO, 2010: 296).

Destacando não só a necessidade do "seu Cascudinho"» direcionar sua carreira para a investigação das manifestações folclóricas, mas também da importância de se construir uma rede de sociabilidade que o possibilitasse adquirir informações acerca do seu objeto de estudo. Recomendações que ao serem seguidas, por Luís da Câmara Cascudo, resultaram na produção de obras.

A classificação de Mário de Andrade como pioneiro nos estudos do campo folclórico tem relação com a troca de correspondências que estabeleceu com folcloristas de diversas regiões, a exemplo do que realiza com Luís da Câmara Cascudo. Característica que permitiu o exercício de atividades em prol da institucionalização da pesquisa folclórica por meio da ocupação de cargos políticos e institucionais, como o faz ao ser convidado pelo potiguar para apossar-se de posto na Sociedade Brasileira de Folclore.

A aproximação com Mário de Andrade se intensificou pela posição ocupada por ambos no Instituto Nacional do Livro (INL). Sendo este responsável pelo projeto da Enciclopédia Brasileira e aquele pela confecção do dicionário que passou a acompanhála, evidenciando a similaridade nos objetivos desses empreendimentos. Além disso, há a presença de ambos nos círculos modernistas o que proporcionou, entre outras questões,

\footnotetext{
4 “Do seu Cascudinho" era uma das formas empregadas por Luís da Câmara Cascudo para assinar as correspondências enviadas a Mário de Andrade.
} 
que desenvolvessem afinidades comuns, a exemplo da interpretação de que o folclore é um caminho para a reflexão em torno do elemento nacional.

As correspondências entre Luís da Câmara Cascudo e Mário de Andrade podem ser interpretadas como possibilidade para que o escritor potiguar atualizasse a província com o cenário cultural do centro-sul por meio da divulgação de revistas literárias, resenhas de livros e outras ações que foram intermediadas pelo folclorista paulista, como quando encaminha carta, em 29 de abril de 1930, mencionando ao potiguar que o “Diário Nacional quer colaboração semanal de você, é possível? [...] Pagamento, tomo conta disso, fique sossegado. Eu ficava (sic) muito alegre vendo você colaborar aqui" (grifo no original) (MA, 29-IV-1930, apud, CASCUDO, 2010: 171). A cooperação que se institui a partir do recebimento dessa solicitação é conteúdo de algumas das missivas posteriores, visto que Mário de Andrade se designa como intermediário entre Luís da Câmara Cascudo e o periódico. Assim, em 12 de setembro de 1930, após o envio de alguns artigos para publicação no Diário Nacional, o folclorista potiguar encaminha carta justificando a interrupção na contribuição, relatando que "o transtorno em minha colaboração vem de um imprevisto. Minha mulher adoeceu e durante três meses, desde junho, ando para cima e para baixo, catando melhoras para ela" (CC, 12-IX-1930, apud, CASCUDO, 2010: 183). O que o leva a perguntar, em 05 de dezembro de 1930, se o "Diário Nacional ainda aceita colaboração ou a suspende. Eu tenho esperanças de arranjar, pelo tempo adiante uns jornais cariocas e ou paulistas onde escreva. Você quando surgir ocasião aja em meu nome, mano!” (grifo no original) (grifo nosso) (CC, 05-XII-1930, apud, CASCUDO, 2010: 188), destacando a necessidade de conseguir estabelecer alguma cooperação com periódicos daquela região, visto que, é acometido pela intermitência no pagamento das crônicas que publicava no jornal norterio-grandense A República. Em resposta, Mário de Andrade indica ir "hoje mesmo ao Diário Nacional, tratar do seu caso e ver se querem continuar a colaboração" (grifo no original) (MA, 23-XII-1930, apud, CASCUDO, 2010: 189), além disso, alude ao desconforto em continuar cooperando, pois, a mudança na direção do periódico desencadeou uma sensação de não pertencimento àquele espaço, por isso, o pedido feito por Luís da Câmara Cascudo ocasionaria certo incômodo.

Em outros momentos, Mário de Andrade agiu novamente como mediador dos projetos cascudianos a exemplo de quando o folclorista potiguar o responsabiliza pelo acompanhamento no processo de publicação de uma de suas obras. Dessa forma, em 28 de março de 1927, redige para o poeta relatando que "se isto acontecer tudo espero de 
você aí para a última vista de olhos nas páginas, escolha de papel e acima de tudo, capa. Uma capa simples, sólida e bonita. Bem espessa" (CC, 28-III-1927, apud, CASCUDO, 2010: 125). Posteriormente, em 30 de abril de 1927, o próprio escritor paulista solicita que o norte-rio-grandense "prepare os originais do seu livro que quer editar aqui. Estou inteiramente às ordens na vida como na morte" (MA, 30-IV-1927, apud, CASCUDO, 2010: 130). A cooperação perpassa outros meios de publicação, como retrata a missiva na qual Mário de Andrade responde a Luís da Câmara Cascudo que pode contar "com minha colaboração pra sua revista e se quiser a de mais alguém escolha e diga. Tratarei de arranjar" (grifo nosso) (MA, 06-IX-1925, apud, CASCUDO, 2010: 64), sugerindo a possibilidade de intermediar alguma contribuição intelectual.

Ao contrário do que uma análise unilateral parece sugerir, não só Luís da Câmara Cascudo recebeu benefícios em sua carreira a partir da troca de correspondências com Mário de Andrade, pois o poeta também foi favorecido. Benesse que, em algumas situações, alude para um coletivo que é intermediado por algum dos correspondentes. No caso da missiva de 27 de abril de 1931, Luís da Câmara Cascudo é solicitado para que indique e convoque algum pesquisador para colaborar na Revista Nova ${ }^{5}$. Assim, o folclorista paulista questiona se o potiguar "não conhece aí pelo Nordeste gente bem abalizada em qualquer assunto, gente bem taco que pudesse escrever alguma coisa pra nós [...] pode convidar em nosso nome, mas sempre tomando cuidado que seja gente de taco" ${ }^{6 \prime}$ (grifo nosso) (MA, 27-IV-1931, apud, CASCUDO, 2010: 199).

Porém, o maior número de benefícios, resultantes da parceria estabelecida a partir da prática epistolar, remete a colaborações que partiam de um dos intelectuais, como indica a solicitação que acompanha o conteúdo da correspondência, encaminhada por Mário de Andrade em 01 de março de 1927, na qual demanda a Luís da Câmara Cascudo o envio de material para compor uma de suas obras.

Ora o que eu quero de você é isto: você tem recolhido lendas e tradições aí do Nordeste. Meu livro já está escrito porém tenho ainda um ano pra matutar sobre ele e modificá-lo à vontade. Eu queria botar uma lenda aí do

\footnotetext{
${ }^{5}$ Mário de Andrade foi um dos fundadores da Revista Nova, periódico que circulou entre os anos de 1931 e 1932 em São Paulo. Autoproclamada como destinada a uma minoria, a revista apresentava como objetivo transpor o "imenso atraso intelectual" do país por meio daquilo que denominava de repertório do Brasil, isto é, destinava-se ao autoconhecimento do brasileiro. Nessa perspectiva, seria construída com auxílio de historiadores, críticos e folcloristas como Luís da Câmara Cascudo, que tem seu nome estampado na capa da edição inaugural.

6 A expressão "gente de taco" significa que Mário de Andrade desejava que os indivíduos convidados, para colaborar no periódico, fossem hábeis e/ou especialistas em algo.
} 
Nordeste nele, você não pode me ceder uma das que recolheu? Quero uma bem lírica, sentimental se for possível. Enfim o mais lírica possível. Escolha das que você tem umas duas ou três e me mande. Botarei uma só e guardarei cuidadosamente as outras pra você mesmo (grifo nosso) (MA, 01-III-1927, apud, CASCUDO, 2010: 123).

Mário de Andrade ao revelar estar familiarizado com o desenvolvimento das pesquisas cascudianas utiliza a carta como espaço propício para o compartilhamento da criação intelectual, tanto pela menção do estágio da produção quanto por utilizá-la como mecanismo para obtenção de informações, no caso as lendas, para compor o conteúdo da obra. Além disso, ao mencionar que guardará parte do material para o Luís da Câmara Cascudo do futuro certifica a posição de incentivador da produção folclórica do amigo.

Visando estabelecer uma ampla rede de contatos, o potiguar o apresenta a escritores da América Latina, como retrata a missiva, encaminhada em 09 de dezembro de 1925, na qual menciona que "o argentino-colombiano Luis Emilio Soto leu o Escrava duas vezes e está suando de entusiasmo. Mandei seu endereço para que ele enviasse a crônica a respeito do livro" (CC, 09-XII-1925, apud, CASCUDO, 2010: 80). Posteriormente, em 17 de abril de 1927, Luís da Câmara Cascudo escreve "você gosta do Eugenio D’Ors? Quer acamaradar-se?" (grifo nosso) (CC, 17-IV-1927, apud, CASCUDO, 2010, 127), indicando a possibilidade de intermediar uma parceria intelectual entre o escritor espanhol e Mário de Andrade.

O compartilhamento de pareceres acerca das produções intelectuais, confeccionadas por si ou por terceiros, permeia o conteúdo das correspondências cascudianas. Com Mário de Andrade, por exemplo, a escrita desenvolvida pelo folclorista potiguar é constantemente objeto de apreciação. Nessa perspectiva, a análise desenvolve-se como, na carta enviada em 1926, quando o escritor paulista referencia alguns dos poemas produzidos por Luís da Câmara Cascudo, encaminhados anteriormente, desaprovando a circunstância na qual eles se encontram, isto é, arquivados. A partir disso, o conteúdo epistolar manifesta certo tom glosador, alertando sobre a necessidade de confeccionar seus escritos com paciência, de forma que observe a relevância de realizar consertos no que foi elaborado, indicando que

você vai me tirar imediatamente do "inferno da biblioteca" como escreveu, os seus livros de versos e vai relê-los e trabalhá-los [...] isto não é só um pedido social não, é ordem de amigo, coisa que se cumpre num átimo sem raciocinar. Deixe-se de preguiça e de tolice, escrever sem consertar depois o que a própria rapidez e veemência de inspiração enfraquece não dá coisa boa 
quase nunca. Se o gênio não é uma longa paciência como queria o outro, é incontestável que sem paciência e trabalho refletido, que só pode ser posterior ao momento da criação, não tem quase obra que seja grande (grifo nosso) (MA, Ano-Bom-1926, apud, CASCUDO, 2010: 84).

Posteriormente, a ausência de paciência é novamente criticada por Mário de Andrade. Na missiva datada de 22 de julho de 1926, ao avaliar o material enviado por Luís da Câmara Cascudo acerca do folclore nacional, sugestiona que ele aja com calma para que a pesquisa folclórica tenha consistência e possa originar uma obra monumental, assim, alerta para que

tome bem cuidado porque tenho a impressão pelo lido e se você colher com paciência o maior número de lendas possível e as der no livro, tenho a impressão que a obra fica um monumento. E é mesmo por isso que sou severo assim. Com artigo o pedaço que você me mandou impresso ainda passa [...] porém como livro exijo e sei que você pode dar coisa fortíssima (grifo nosso) (MA, 22-VII-1926, apud, CASCUDO, 2010: 113-114).

A inquietação, mencionada por Mário de Andrade, desenvolvida por Luís da Câmara Cascudo ao produzir os seus escritos ocasiona a execução simultânea de projetos díspares, o que é motivo de julgamento do poeta. Em correspondência, de 22 de janeiro de 1928, menciona que, apesar das produções cascudianas serem permeadas por um frequente "interesse brasileiro" (MA, 22-I-1928, apud, CASCUDO, 2010: 141), o folclorista deveria focar na elaboração de uma obra por vez e de preferência que essa seja relativa às tradições nacionais, assim, indaga

Pra quê que você em vez de dar fim pras Lendas e Tradições já encaminhadas se mete fazendo mais projeto de livro e inda mais o enorme do livrão em três volumes que projetou? [...] o que vejo nessa porrada de projetos encolarados é o espírito dispersivo se intrometendo na dança e não deixando você puxar fieira direito (grifo nosso) (MA, 22-I-1928, apud, CASCUDO, 2010: 141).

O estilo desenvolvido por Luís da Câmara Cascudo é objeto de reflexão do próprio potiguar que em 28 de abril de 1926 informa o estágio no qual se encontra a sua escrita relatando que "meu livro vai se arrastando, foram surgindo notas e mais notas e eu fui aproveitando, aproveitando, desdobrando, cotejando e o livro crescendo como rabo de orçamento" (grifo nosso) (CC, 28-IV-1926, apud, CASCUDO, 2010: 102). Tal alusão nos permite compreender que o seu processo de criação engloba uma pesquisa que laboriosamente se consuma, visto que, padece de constantes acréscimos. Posteriormente, em 18 de maio de 1926, nos concede outra pista sobre o que determina a lentidão no seu processo de escrita, trata-se do desenvolvimento de ofícios 
simultâneos, dessa forma, revela que "estou arrastando os livros porque me meti com meu Pai em comércio" (CC, 18-V-1926, apud, CASCUDO, 2010: 105). No Domingo de Páscoa de 1927, Luís da Câmara Cascudo escreve a Mário de Andrade em resposta ao questionamento feito pelo escritor paulista acerca da evolução das suas pesquisas, alegando que a interrupção no processo de escrita deve-se ao desejo de produzir algo amadurecido, assim, o silenciamento acerca dos livros diz respeito à circunstância de que "não quero dar um artigo. Nem uma nota. Desejo bater um ensaio, livro bem vivido, com traços pessoais de correspondência, de observação e de lembrança física" (grifo nosso) (CC, 17-IV-1927, apud, CASCUDO, 2010: 127).

Apesar, da criticidade que permeia a escrita de Mário de Andrade, e se revela em algumas das avaliações das obras de Luís da Câmara Cascudo, as correspondências anunciam exaltações como a que realiza quando glorifica a produção de uma pesquisa etnográfica e frisa a importância de que ele continue empenhado na confecção da obra acerca da literatura oral, apontando-a como possível complementação e motivo de aclamação. Assim, menciona que "quanto à arquitetura do Etnografia tradicional do Nordeste brasileiro achei muito boa, sempre contando com o livro Literatura oral que virá completá-lo depois. Será o seu monumento, mano e só pensar nisso já vou ficando feliz, feliz, é bom ter manos" (grifo nosso) (MA, 06-VIII-1929, apud, CASCUDO, 2010: 163-165). Enaltecimento semelhante ao que emprega na carta escrita durante o carnaval de 1944 quando se refere à obra Antologia do Folclore Brasileiro, indicando que se tornará referência e meio de consulta, desse modo, afirma

estive outro dia na Livraria Martins e ele me mostrou as provas da sua antologia folclórica, vai sair um livrão nos dois sentidos. Estive compulsando o seu trabalho. Franqueza: é excelente. Quanta gente agora vai bancar o "científico" citando as fontes através do canal que você lhes abriu (grifo nosso) (MA, 22-II-1944, apud, CASCUDO, 2010: 328).

A exaltação das obras produzidas por Luís da Câmara Cascudo, que figurava nas missivas, era produzida não só por aqueles com quem se correspondia e solicitava apreciação das pesquisas, mas pelo próprio folclorista. Nessa perspectiva, em relação à obra Poética Sertaneja ele declara, em 08 de junho de 1931, que reflete uma pesquisa única tanto por abarcar "documentação inédita e original” (CC, 26-VIII-1931, apud, CASCUDO, 2010: 216), quanto por distinguir-se do que foi feito até então, pois "até aqui. Você deve ter notado que os folcloristas revelam a poesia sertaneja sem a menor explicação de sua evolução e técnica [...] Só se fala em martelo e colcheia e ninguém 
diz o que é e como se formou [...] Eu tentei fazer uma coisa assim" (grifo nosso) (CC, 08-VI-1931, apud, CASCUDO, 2010: 206), isto é, o que foi produzido por Luís da Câmara Cascudo diferencia-se das demais por contemplar reflexões em torno da emergência - caracterizando a busca pelas origens, um dos estágios da pesquisa folclórica - e definição de tal elemento. Além disso, quando questiona Mário de Andrade acerca das suas impressões relativas à obra, Luís da Câmara Cascudo garante que "não conheço em folclore coisinha parecida com aquele jeito" (CC, 08-VI-1931, apud, CASCUDO, 2010: 206).

Posteriormente, em 29 de fevereiro de 1944, declara pensar em confeccionar um segundo tomo da obra citada por Mário de Andrade como um "trabalhão útil” (MA, 13VIII-1944, apud, CASCUDO, 2010: 336), mas suas ressalvas partem do que ironiza denominar de "os "folcloristas" brasileiros são três ou quatro e os "folcloristas oficiais" são uns quarenta" (CC, 29-II-1944, apud, CASCUDO, 2010: 332), ou seja, a parcela daqueles que Luís da Câmara Cascudo considera como propriamente folcloristas não é condizente com a quantidade que se intitula como tal. Além disso, ressalta que o posicionamento folclórico que apresenta seria motivo de desavenças, assegurando que "não quero brigar". Sou o único a não brigar mesmo quando se trata da suprema tentação exibicionista de discutir escolas" " (CC, 29-II-1944, apud, CASCUDO, 2010: $332)$.

Porém, a epistolografia cascudiana não foge à discussão acerca de movimentos folclóricos e literários. Como ocorre a partir do recebimento da correspondência de Mário de Andrade em 26 de setembro de 1924, quando uma conversação acerca do Movimento Regionalista é despertada. O paulista inicia afirmando estar fugindo do regionalismo, enquanto pensamento literário, por considerá-lo uma ameaça, assim, acaba por nos apresentar certo direcionamento na sua produção intelectual. Além de, ao aconselhar que o escritor norte-rio-grandense faça o mesmo, assinala a ânsia por

\footnotetext{
7 As pesquisas realizadas por Luís da Câmara Cascudo interessavam principalmente aos folcloristas estrangeiros, o que gerava desavenças com outros intelectuais a exemplo de Renato Almeida. Este considerava que o direcionamento para o âmbito internacional só deveria ser feito quando o debate folclórico já estivesse consolidado no contexto nacional.

${ }^{8}$ Luís da Câmara Cascudo e Mário de Andrade apesar de, convergirem ao entender o folclore como melhor caminho para preservação da cultura nacional, e compreenderem o seu registro como empreendimento indispensável no período de modernização do país, em alguns momentos, apresentavam pensamentos dispares no tocante a relação que tal elemento estabelecia com o avanço da modernidade. $\mathrm{O}$ primeiro acreditava na sobrevivência do folclore, apesar de supor que esse iria perder suas características originais ao realizar transformações para se adaptar à nova realidade, já o segundo considerava que o desenvolvimento do progresso acarretaria uma perda dos costumes folclóricos, discurso caracterizado por uma retórica da perda.
} 
estabelecer uma aproximação intelectual por meio de outro movimento artístico, isto é, o Modernismo, processo que só seria permitido "graças a essa "fuga do regionalismo" (MA, 26-IX-1924, apud, CASCUDO, 2010: 38). O debate acerca do Movimento Regionalista iria figurar o conteúdo de outras missivas trocadas entre Mário de Andrade e Luís da Câmara Cascudo, a exemplo da enviada em 01 de março de 1927 na qual o poeta declara ter misturado "completamente o Brasil inteirinho como tem sido minha preocupação desde que intentei me abrasileirar e trabalhar o material brasileiro. Tenho muito medo de ficar regionalista e me exotizar pelo resto do Brasil" (grifo nosso) (MA, 01-III-1927, apud, CASCUDO, 2010: 123).

A missiva de 22 de agosto de 1925, enviado por Luís da Câmara Cascudo ${ }^{9}$ para Mário de Andrade, tem como anexo "o convite ${ }^{10}$ para o Primeiro Congresso Regionalista do Nordeste" (CC, 22-VIII-1925, apud, CASCUDO, 2010: 55) e a sugestão para que "se você não tem tempo de rabiscar em cima de alguma tese, assinale uma ou umas" (CC, 22-VIII-1925, apud, CASCUDO, 2010: 55). Em 06 de setembro de 1925 o folclorista paulista responde a carta indicando abraçar tal proposta e imbuindo o potiguar de divulgar tal acordo. Porém, tece algumas críticas relacionadas ao conteúdo elencado no programa, ressaltando sua oposição ao pensamento regionalista, apesar de salientar que

O tal do Congresso Regionalista me deixou besta de entusiasmo. Em tese sou contrário ao regionalismo. Acho desintegrante a ideia de nação e sobre este ponto muito prejudicial pro Brasil já tão separado. Além disso fatalmente o regionalismo insiste sobre as diferenciações e as curiosidades salientando não propriamente o caráter individual psicológico de uma raça porém os seus lados exóticos [...] Se a minha adesão vale de alguma coisa aí vai sincera com uma enorme saudade mandada pra esse Nordeste (grifo nosso) (MA, 06-IX-1925, apud, CASCUDO, 2010: 64).

Após empreender viagem para Recife, sede do Movimento Regionalista, Luís da Câmara Cascudo escreve correspondência para Mário de Andrade proclamando que ao se deparar com aquilo que denomina de "gente moderna do Norte" (CC, 09-XII-1925, apud, CASCUDO, 2010: 79) permaneceu melancólico. A partir disso, descreve a capital pernambucana por meio do emprego de termos relativos à influência estrangeira, assim, afirma ter deduzido

\footnotetext{
${ }^{9}$ Sobre a relação entre Luís da Câmara Cascudo e o Movimento Regionalista. Cf. NETO (2008).

${ }^{10} \mathrm{O}$ programa-convite do I Congresso Regionalista do Nordeste é produzido por Gilberto Freyre e Olidon Nestor.
} 
o que vem a ser o "intelectualismo" de lá. É unicamente elegante, brunido, bebedor de chá, lambedor de sorvete, dançador de fox e guiador de automóvel. Nada íntimo, intenso, sentido, subjetivo, real, integralizando o sonho no trabalho. Você, seu Mário, é ali em Recife, um ser anormal, enorme, gigantesco, temido, apavorando tudo (grifo nosso) (CC, 09-XII1925, apud, CASCUDO, 2010: 79).

Anteriormente, em 19 de maio de 1925, Luís da Câmara Cascudo direciona correspondência para Mário de Andrade declarando que o escritor paulista conquistou um amigo e, por isso, ressalta o desejo de que o poeta faça uma visita ao Norte ${ }^{11}$, passando tanto pelo Rio Grande do Norte quanto por Pernambuco, oferecendo a sua casa como hospedagem e indicando o desejo de fazê-lo conhecer "casas, vaqueiros, lobisomens, matutos, anedoteiros" (CC, 19-V-1925, apud, CASCUDO, 2010: 40-41). Encontro que poderia ser intermediado por contribuição do folclorista potiguar, como é sugerido pelo paulista quando solicita que Luís da Câmara Cascudo "arranje com o Inojosa pra me convidar do Recife pra conferência lá" (MA, 03-II-1926, apud, CASCUDO, 2010: 90) ruminando acerca dos custos de tal deslocamento e concluindo que "se as conferências renderem uns dois contos creio que bastará isso, não?" (MA, 03-II-1926, apud, CASCUDO, 2010: 90). O questionamento refere-se às despesas do itinerário que pretendia percorrer, assim, o intermédio de outros intelectuais possibilitaria que, além de divulgar-se nas conferências, angariasse recursos para a execução dos seus planos de viagem.

Ainda imbuído do desejo de inspirar Mário de Andrade a concretizar o deslocamento, Luís da Câmara Cascudo envia outra missiva, dessa vez, acompanhada de uma fotografia da Praia da Redinha em Natal, com isso afirma "receba e mire o Rio Grande do Norte" (CC, 21-V-1925, apud, CASCUDO, 2010: 42), declarando que nela está retratado o vaqueiro legítimo. Trata-se de uma carta significativa por comunicar que está "folclorizando", isto é, envolto no desenvolvimento de alguma pesquisa folclórica.

Mário de Andrade redige resposta em 26 de junho de 1925 e, estimulado pelo recebimento da fotografia, reitera tanto que "tem fome pelo Brasil" (MA, 26-VI-1925, apud, CASCUDO, 2010: 47) - motivada por aquilo que denomina de ânsia brasileira quanto revela a aspiração por visitá-lo no Norte. Por meio do envio do poema acreano evidencia-se o direcionamento da missiva para o compartilhamento intelectual,

\footnotetext{
${ }^{11}$ A ideia de "Nordeste" se concretiza a partir de inúmeros discursos que respaldaram a sua "invenção". Até então essa região era denominada de "Norte" e seus habitantes "nortistas". Cf. ALBUQUERQUE, JR. (2009)
} 
ampliado a partir da afirmação sobre o interesse nos resultados do processo de "folclorização", mencionado anteriormente por Luís da Câmara Cascudo, curiosidade que seria ocasionada porque são resultados do trabalho de uma inteligência admirada pelo poeta e por serem confeccionados por seu amigo. Ressaltando que, nas correspondências, a sinergia entre ambos extrapola o campo intelectual e adentra o domínio privado.

\section{Quando o "eu privado" sobrepõe o "eu social"}

A correspondência, enquanto documento expressivo, é interpretada como texto propício ao compartilhamento de informações tanto sobre questões culturais, políticas e literárias quanto àquelas que se referem a uma escrita de si, abarcando, consequentemente, questões pessoais e expressões de sentimentos. A estreiteza de laços instituída ao longo das décadas de conversação oportunizou que Luís da Câmara Cascudo e Mário de Andrade revelassem momentos das suas trajetórias intelectuais, assim como promovessem uma abertura total entre os correspondentes, expondo situações nas quais o "eu social" é sobreposto pelo "eu privado".

A epistolografia manifesta sentimentos como desânimo, entusiasmo e outros que se expressam não só pelas palavras que contém, mas por elementos como os silêncios, inclusive a ausência ${ }^{12}$ de respostas e/ou o envio de outros tipos de correspondências como os bilhetes ${ }^{13}$, telegramas e outros - ocasionam uma quebra da relação de intimidade e confiança que foi estabelecida na troca de cartas. Além disso, a falta de correspondências se caracteriza como conteúdo recorrente na conversação estabelecida entre ambos, assim, em certos momentos há o emprego de súplicas para que a comunicação logre de uma continuidade. Como sugere a missiva enviada por Mário de Andrade, em 01 de março de 1927, na qual, o poeta, após um período marcado pela ausência de correspondências enviadas por Luís da Câmara Cascudo, questiona o correspondente acerca do que motivou tal interrupção, demonstrando a insatisfação por não receber resposta e sugerindo certa ingratidão do amigo. Assim, escreve

\footnotetext{
12 Concebida como capaz de suprir o distanciamento ao simular uma proximidade entre os correspondentes, a epistolografia acaba por manter a distância, já que pode ser interpretada como um meio de preservar a solidão na medida em que as pessoas se correspondem porque estão sós.

${ }^{13} \mathrm{O}$ recebimento de bilhetes, em alguns momentos, não era bem interpretado pelos correspondentes, pois devido à agilidade com que apresentavam o conteúdo não obedeciam a um detalhamento insatisfazendo aqueles que desejavam o estabelecimento de uma conversação prolongada. Luís da Câmara Cascudo, por exemplo, critica Mário de Andrade em 07 de março de 1928 e 19 de outubro de 1941 pela brevidade com a qual o amigo escreve, sugestionando o desagrado que a ausência de informações ocasiona.
} 
Pois é: ando desapontado com a indiferença de você. Escrevo, eu que tenho três vezes mais que o dia de que fazeres, escrevo assim mesmo roubando tempo da vida e você nem pio... Isso não se faz Luís (grifo nosso) (MA, 01-III-1927, apud, CASCUDO, 2010: 122).

O clamor que compõe algumas das correspondências revela-se ainda nas solicitações que as acompanham. Portanto, os pedidos redigidos por Luís da Câmara Cascudo e Mário de Andrade não reportavam apenas ao campo intelectual, mas também a questões do âmbito privado, como indica a carta produzida pelo folclorista potiguar, em 02 de março de 1932. Nela, menciona a saúde debilitada de seu pai, o Coronel Cascudo, manifestando precisar que o poeta lhe realize um favor. Dessa forma, reporta estar escrevendo

às pressas para pedir-lhe um obséquio de identificar na indicação inclusa onde é que se vende o tal sal que meu pai precisa urgentemente. Aqui as farmácias vendem abusivamente e a porção que trouxe de Recife está se esgotando rapidamente. Agradeceremos muitíssimo se o querido "compadre" tiver a bondade de enviar-nos umas (sic) cinquenta gramas desse sal e, artigo primeiro e indispensável, o preço que é para ficarmos comprando aí e reembolsaremos o prestadio "compadre". Creio que muito e muito agradeceremos pois se trata do condimento único que meu pai usa em sua alimentação (grifo nosso) (CC, 02-III-1932, apud, CASCUDO, 2010: 228).

Pedido que é reiterado na correspondência seguinte, em 14 de março de 1932, quando menciona o envio da missiva anterior e ressalta a necessidade de que o escritor paulista atenda a súplica, apontando ter mandado "pelo outro correio uma apressada cartinha pedindo um sal para papai [...] Peço que você não esqueça o sal e especialmente o endereço e respectiva nota porque já não tem graça nenhuma ficar eu eternamente devedor nas duas espécies, moral e material” (CC, 14-III-1932, apud, CASCUDO, 2010: 229). Solicitação de ordem semelhante é feita posteriormente, em 04 de maio de 1935, quando Luís da Câmara Cascudo escreve a partir do Rio de Janeiro e narra ter encontrado "uma carta aérea de papai pedindo sementes de verduras e hortaliças paulistanas" (CC, 04-V-1935, apud, CASCUDO, 2010: 269), porém, à distância o impediria de realizar tal desejo, por isso pede que Mário de Andrade

acuda na emergência, mandando, diretamente para Natal, sementes de chuchu, pepino, couve-flor, pimentão grande (verde, vermelho e amarelo) e demais excelências da horta [...] Não esqueça, seu Mário. Se o papai (!) ficar sem as sementes a culpa será exclusivamente sua (CC, 04-V-1935, apud, CASCUDO, 2010: 269). 
Acerca de tal pedido, o potiguar diverte-se mencionando que o poeta escapou de cumprir uma solicitação anterior, isto é, o envio da obra Almanaque de Ghota requerida anteriormente. Mas, dessa vez, os "interesses são mais altos, pessoais e gostosos" (grifo nosso) (CC, 04-V-1935, apud, CASCUDO, 2010: 269), por isso, deveria compreendê-lo com paciência e responder a encomenda.

A correspondência indica que além de uma parceria intelectual há um partilhamento da vida desses sujeitos, sugestão que também se representa no conteúdo vinculado na missiva de 07 de janeiro de 1931 quando Luís da Câmara Cascudo encaminha o pedido para que Mário de Andrade seja padrinho de seu filho, Fernando Luís da Câmara Cascudo. Desejando, por meio desse, instituir um vínculo duradouro com o poeta. Assim, relata que "espero um filho que se chamará Fernando Luís e que Mário de Andrade levará para o senhor Bispo passar os santos óleos da crisma. Desta forma prendo você a uma entidade viva e humana, afora Macunaíma-o-eterno" (grifo nosso) (CC, 07-I-1931, apud, CASCUDO, 2010: 192).

O caráter privado da epistolografia se intensifica quando as correspondências despertam o compartilhamento emocional entre o destinatário e o remetente. No caso de Luís da Câmara Cascudo e Mário de Andrade isso ocorre quando celebram, rememoram e evocam sentimentos, a exemplo das lamentações expostas em epístolas como a enviada pelo poeta em 17 de julho de $1935^{14}$. Nela, Mário de Andrade lamenta o falecimento do pai do folclorista, o Coronel Cascudo, e partilha do sentimento de luto vivenciado pelo amigo, declarando preferir silenciar, pois desistiu de

lhe dizer palavras de sofrimento e de conforto, pela morte do coronel Cascudo. Quase cotidianamente tenho pensado em escrever pra você, desde que soube do desastre, mas meus braços caem logo sem vontade, e me fico amargando pelas deficiências da escritura, pelos seus imprescindíveis lugares-comuns de língua de todos e não de um só. E eu queria me dizer sozinho, menos aliás no que eu sofri por mim, que também queria um enorme bem a esse velho admirável, do que no desejo de compartir com você e os seus do sofrimento novo, acarinhá-los em tudo o que o meu coração tem de mais espontâneo, de mais impulsivo, e é tão ardente, tão sincero no momento. Mas é melhor nem falar... Embora eu parecesse ausente nestes tempos, basta que você relembre toda a felicidade do que tem sido o nosso convívio, pra imaginar que também neste momento eu não estava ausente, estava silencioso, isso sim. Mas pensava muito, pensava mesmo sem a menor procura de pensar, como a naturalidade espontânea do

\footnotetext{
${ }^{14}$ Após o envio dessa correspondência há uma interrupção na conversação, que só é retomada por Luís da Câmara Cascudo em 14 de fevereiro do ano seguinte. Os comentários acerca de possíveis pausas no processo de escrita das correspondências as aproximam de uma conversa por escrito, indicando o registro de acontecimentos em torno daqueles que se comunicam. Porém, em alguns momentos, como o da missiva mencionada a interrupção não é justificada.
} 
meu ser, em você, em dona Ana, em todos (grifo nosso) (MA, 17-VII-1935, apud, CASCUDO, 2010: 270).

Em alguns momentos, as lamúrias na epistolografia de ambos remetem a questões de ordem intelectual como a que acompanha a missiva enviada em 18 de junho de 1937. Na correspondência, que despertaria uma das conversações mais significativas entre ambos, Luís da Câmara Cascudo preconiza a necessidade de uma pausa nos afazeres pedindo que o amigo o compreenda e ceda ao pedido "para desobrigar-me do que é para mim materialmente intransponível" (CC, 18-VII-1937, apud, CASCUDO, 2010: 297). Além disso, na correspondência o folclorista, ao agradecer a compreensão do momento que, em carta anterior, declarou estar vivenciando, expõe sentimentos como "tristeza, desânimo, apatia, solidão" (CC, 18-VII-1937, apud, CASCUDO, 2010: 297) indicando que ao sentir-se assim tem no correspondente a imagem de um confidente, por isso "o meu berro instintivo e natural foi para você. Deduza daí a confiança, certeza, a lealdade em que tenho nossa velha amizade" (grifo nosso) (CC, 18-VII-1937, apud, CASCUDO, 2010: 297).

Nas correspondências há o imbricamento entre queixas relativas ao fazer intelectual e as de ordem particular, visto que, em determinado momento, Luís da Câmara Cascudo encaminha carta para o amigo lamentando embolsar "uma miséria como professor" (CC, 09-VI-1937, apud, CASCUDO, 2010: 291) e declarando estar vivenciando adversidades, pois "dez pessoas de família que sustento não podem esperar pão de outra parte" (CC, 09-VI-1937, apud, CASCUDO, 2010: 291). Indicando ainda que o auxílio do companheiro "servir-me-ão para o leite de Ana Maria" (CC, 09-VI1937, apud, CASCUDO, 2010: 291), por isso, solicita que Mário de Andrade interceda para que o folclorista obtenha alguma colaboração remunerada em periódico de São Paulo.

O desabafo ocasiona resposta imediata do escritor paulista que, no mesmo dia, escreve mostrando-se impressionado com a aflição demonstrada nas linhas escritas pelo folclorista potiguar. Manifestando que

o único arranco que posso dar é quanto ao Estado de S. Paulo. Nos outros jornais não tenho positivamente possibilidade de conseguir coisa nenhuma [...] Dei ainda providências quanto à minha (hélas, enquanto for diretor do D. de C.) Revista do Arquivo. Você me faça dois artigos por ano a duzentos mil-réis casa um. Você compreende, sei, mais não posso encomendar, porque monotonizaria a revista. Prefiro trabalhos sobre folclore (grifo no original) (grifo nosso) (MA, 09-VI-1937, apud, CASCUDO, 2010: 292). 
O prenúncio de que optaria por estudos folclóricos assinala o percurso que a correspondência irá seguir, direcionando-se para o desabafo e a exposição de críticas ao labor realizado por Luís da Câmara Cascudo. Nessa perspectiva, o poeta atesta que "[...] apesar da tristeza, não ser momento bom para rispidez, você vai me permitir, duma vez por todas, que fale com franqueza sobre os seus artigos. Geralmente não gosto abertamente deles, e agora careço dizer por quê" (grifo nosso) (MA, 09-VI-1937, apud, CASCUDO, 2010: 292). A menção de que a opinião emitida será verdadeira sugestiona que, em certa medida, até aquele momento, Mário de Andrade camuflava o seu posicionamento nas correspondências direcionadas ao intelectual norte-rio-grandense, $o$ que acaba por confirmar ao declarar que

Minhas cartas, nesse sentido, sempre foram com algumas reticências, que no entanto, jamais existiriam quando eu te incitava a trabalhar e dava deixas sobre assuntos em que você podia produzir obras de real valor. Porque não terei sido totalmente franco? Meu Deus! Nem sei bem... Um pouco de fadiga, um pouco medo de ferir você porque sinto você um bocado vaidoso, talvez erre. Mas nunca deixei de considerar o valor de você e a sua inteligência. Minha convicção é que você vale muito mais de que o que já produziu (grifo nosso) (MA, 09-VI-1937, apud, CASCUDO, 2010: 292293).

Silêncio que surpreendeu o próprio Luís da Câmara Cascudo que, ao responder a carta, relata ter a impressão de que "você sempre me teve como uma força e potencial, uma grandeza in being ${ }^{15}$ [...] Julgou-me pelo que eu seria capaz e nunca pelo que fiz. Não só se deduz pelos doze anos que você esperou para dizer-me, assim como pelo silêncio anterior" (grifo nosso) (CC, 18-VI-1937, apud, CASCUDO, 2010: 297). A omissão rompe o pacto de sinceridade estabelecido entre os correspondentes e desconsola aquele que creu obter franqueza na conversação, a surpresa atinge o folclorista e institui o silêncio, transformando-se em um abandono de defesa, assim, contestar a opinião do correspondente ou mesmo promover um "entendimento literário" (CC, 18-VI-1937, apud, CASCUDO, 2010: 297) seria "endossar a vaidade denunciada por você" (CC, 18-VI-1937, apud, CASCUDO, 2010: 297), por isso, o "melhor é calar" (CC, 18-VI-1937, apud, CASCUDO, 2010: 297).

Os juízos de valor partem daquilo que Mário de Andrade considera como “desprezo da medida”, referindo-se à predileção cascudiana por confeccionar pesquisas sobre figuras de nenhuma relevância, a exemplo da realizada na monografia sobre o Conde d'Eu, assim, questiona "por que você atacou um assunto tão desimportante, uma

\footnotetext{
${ }^{15}$ Em ser [tradução nossa].
} 
figura de nenhum alcance fundamental pra pesquisar tantos dados e dadinhos sobre ela!” (MA, 09-VI-1937, apud, CASCUDO, 2010: 293). Além disso, o julgamento direciona-se para o envolvimento de Luís da Câmara Cascudo com os estudos etnográficos, comentando que

você se meteu logo em quê? em Etnografia, onde positivamente não se pode fazer muita novidade vivendo em Natal ou S. Paulo. Veja o descomedimento: qualquer individuinho que passar dois meses com os Tapirapés, mesmo falho e escrevendo cinco páginas fará coisa de maior interesse etnográfico. Agora: em Natal como S. Paulo urbanos também se pode fazer obra importante de etnógrafo. Mas neste caso será obra de paciência, controle, comparação, análise, multifariedade e enfim síntese (grifo nosso) (MA, 09-VI-1937, apud, CASCUDO, 2010: 293-294).

O trecho ressalta outra discordância relacionada à produção cascudiana, referese ao que Mário de Andrade expôs, em momentos anteriores, e denominou como "falta de paciência", porém, não se trata de uma ausência visto que, demostrou tê-la ao colher referências bibliográficas, citações e dados, mas acaba por empregá-la de maneira equivocada, assim, por este motivo critica a pesquisa sobre Catimbós desenvolvida por Luís da Câmara Cascudo, mencionando que

fui ler o seu estudo, que matou nada! tenho de uns dias de convivência escassa com catimbozeiros uma série de dados muito mais larga e observações muito mais profundas, sem vaidade [...] Fiquei num tal estado de irritação pela sua falta de paciência e leviandade de colheita de documentação, que disse palavras duras, te esculhambei mesmo (grifo nosso) (MA, 09-VI-1937, apud, CASCUDO, 2010: 295).

Ressaltando, por fim, que "seu desprezo da medida faz com que até agora não tivesse paciência pra escrever, senão um livro, pelo menos uma monografia de tema especializado, sobre folclore ao menos do R. Grande do Norte, pra não dizer Nordeste" (MA, 09-VI-1937, apud, CASCUDO, 2010: 295). Os pensamentos expostos por Mário de Andrade acerca dos estudos cascudianos o levam a elencar uma série de observações a respeito dos escritos solicitados para compor a Revista do Arquivo, indicando que devem ser "fundamentais, estudados sério, com paciência, sem leviandade de colheita e exposição de dados" (MA, 09-VI-1937, apud, CASCUDO, 2010: 295).

Ao finalizar a escrita assinalando que "talvez eu nunca esteja tão perto de você como nessa carta triste" (MA, 09-VI-1937, apud, CASCUDO, 2010: 296), o autor de Macunaíma acaba por revelar o pensamento de que as missivas que ostentam confidências, desabafos e outros elementos de ordem particular solidificam os vínculos 
entre aqueles que se correspondem, diminuindo a distância que se impõe entre os sujeitos.

\section{Considerações finais}

As correspondências se caracterizam como uma das etapas fundamentais na constituição do sujeito, já que mesmo em seus estados primários refletem ensaios autobiográficos, conduzindo não a uma busca por si, mas a produção de si. Portanto, guardam a lembrança e a memória dos estados anteriores, trata-se de uma escrita de si, na qual "escrevendo sobre mim, escrevendo-me, aprovo-me ou reprovo-me, nunca sou um testemunho estranho ou indiferente" (DIAZ, 2016: 87).

Nessa perspectiva, não se trata de uma exposição unilateral do sujeito, mas sim uma troca mútua de informações, opiniões, críticas e sugestões entre os intelectuais, Considerando isso, as cartas são vislumbradas como condizentes a traçar a história de um sujeito apresentando dados biográficos e psicológicos, além de servirem para esboçar a história de uma obra.

A prática epistolográfica desenvolvida por intelectuais expõe as coletividades nas quais esses sujeitos transitavam e nos auxiliam a pensar que suas trajetórias ultrapassam as relações estabelecidas nos espaços públicos, compreendendo aspectos da vida privada, visto que, ao transpor o público e adentrar o âmbito privado as correspondências são interpretadas como um espaço seguro, que devido a sua privacidade, torna-se propício a confidência de intimidades e ao compartilhamento de emoções, escapando as convenções e fórmulas de certa norma epistolar.

Portanto, a epistolografia se constitui como um espaço de partilha que possibilita não só abarcar uma variedade de discussões, a exemplo da inserção dos seus produtores e/ou receptores no debate intelectual, mas também atentar para aqueles que são referenciados direta e/ou indiretamente, oportunizando a percepção dos conflitos e/ou afinidades entre intelectuais de uma determinada época.

No caso de Luís da Câmara Cascudo, as correspondências com Mário de Andrade retratam a construção de uma camaradagem ao longo das décadas de conversação, revelando que a prática epistolar possibilita acompanhar o florescimento das relações pessoais, mas também a fragilidade dos relacionamentos humanos. Destacando ainda uma epistolografia que tem a sua importância associada tanto à 
funcionalidade que desempenha quanto ao conteúdo que apresenta. Prática missivista que possibilitou a construção de um espaço de experimentação, no qual os dois escritores realizaram críticas, indicaram obras, compartilharam ideias, estabeleceram parcerias e simbolizaram os interesses que respaldaram essa amizade.

\section{Fontes}

CASCUDO, Luís da Câmara (1954 [1954]). Dicionário do Folclore Brasileiro. Rio de Janeiro: Instituto Nacional do Livro.

.; MORAES, Marco Antonio de (org.) (2010). Câmara Cascudo e Mário de Andrade: cartas 1924-1944. São Paulo: Global.

\section{Referências bibliográficas}

ALBUQUERQUE JR., Durval Muniz de (2009). A invenção do nordeste e outras artes. São Paulo: Cortez.

DIAZ, Brigitte (2016). O gênero epistolar ou o pensamento nômade: formas e funções da correspondência em alguns percursos de escritores no século XIX. Trad. Brigitte Hervot e Sandra Ferreira. São Paulo: EDUSP.

GICO, Vânia Vasconcelos (S/D). Câmara Cascudo: um Hermes Universal no Nordeste do Brasil. Disponível em <https://silo.tips/download/camara-cascudo-um-hermesuniversal-no-nordeste-brasileiro> Acesso em: 14 jul. 2021.

GOMES, Ângela de Castro (2004). Escrita de si, escrita da história. Rio de Janeiro: Fundação Getúlio Vargas.

HAROCHE-BOUZINAC, Geneviève (2016). Escritas Epistolares. Trad. Ligia Fonseca Ferreira. São Paulo: EDUSP.

OLIVEIRA, Giuseppe Roncalli Ponce Leon de (2016). Correspondência de Luís da Câmara Cascudo: arquivos da criação e redes de sociabilidade intelectual. Tese (Doutorado em História). Universidade de São Paulo, São Paulo.

SALES NETO, Francisco Firmino (2008). Palavras que silenciam: Câmara Cascudo e o regionalismo-tradicionalista nordestino. João Pessoa: Editora Universitária.

SIMMEL, Georg; MORAES FILHO, Evaristo de (org.) (1983). Sociologia. São Paulo: Ática.

Artigo recebido em 22 de agosto de 2021.

Aprovado em 09 de dezembro de 2021.

DOI: 10.12957/intellectus.2021.61799 